\title{
Associations between Sense of Coherence and Psychological Work Characteristics with Changes in Quality of Life in Japanese Civil Servants: A 1-Year Follow-Up Study
}

\author{
Ali NASERMOADDELI*, Michikazu SEKINE, Shimako HAMANISHI and \\ Sadanobu KAGAMIMORI
}

\begin{abstract}
Department of Welfare Promotion and Epidemiology, Toyama Medical and Pharmaceutical University, 2630 Sugitani, Toyama 930-0194, Japan
\end{abstract}

Received September 17, 2002 and accepted March 31, 2003

\begin{abstract}
We conducted a 1-year follow-up study to evaluate the lasting effect of psychosocial characteristics on quality of life among Japanese civil servants. For this purpose, sense of coherence (SOC), which has been associated with adoptive measures in responding to life stress, and job strain components of demand and control, were used. We evaluated 1392 civil servants working in departments related to the municipality of $T$ city in Toyama prefecture, Japan, in the springs of 2001 and 2002 with complete information in both phases of the study. Using validated Japanese versions of WHOQOL-BREF (WHO/QOL-26) and SOC-13 and a self-reported questionnaire on job demand and control in the workplace, we conducted multiple linear regression analysis to assess the effects of above-mentioned characteristics on WHO/QOL-26 domains. After entering first phase scores, age, sex, employment category and negative affectivity into the models, SOC was associated positively with second phase scores in all domains of WHO/QOL-26 (standardized $\beta$ coefficients of $0.21, \mathrm{P}<0.01 ; 0.12, \mathrm{P}<0.001 ; 0.13, \mathrm{P}<0.001$ and $0.07, \mathrm{P}<0.05$ for Physical Health, Psychological, Social Relationship and Environment, respectively). In addition job control was related positively to Physical Health, Psychological and Social Relationship domains (standardized $\beta$ coefficient of $0.10, p<0.001 ; 0.12, p<0.05$ and $0.07, p<0.05$, respectively), while job demand was negatively related to Physical Health domain with a $\beta$ coefficient of $-0.11, p<0.001$. Higher sense of coherence and job control could result in better subjective feeling of well-being in a 1-year follow-up among Japanese civil servants.
\end{abstract}

Key words: Quality of life, Sense of coherence, Job control, Job demand, Japan

\section{Introduciton}

The significant influence of the psychological work environment on health has been focused on in a large number of articles ${ }^{1-7)}$. Psychological work environment is mainly resulted from the interaction of two factors of job demand

*To whom correspondence should be addressed. and the degree of control a worker may exert over those demands. Moreover, Antonovsky proposed a sense of coherence (SOC) as a construct that predicts effective coping measures against stressful conditions ${ }^{8-11)}$. SOC has been defined as a global orientation that expresses the extent to which one has a pervasive and dynamic feeling of confidence that the stimuli deriving from one's internal and external environments in the course of living are structured, predictable and explicable. On the other hand, Health related 
quality of life indicators usually encompass a person's ability to perform effectively physically, emotionally and socially and to maintain a sense of well-being ${ }^{12}$. The more traditional biomedical health status measures demonstrate the presence, absence, and severity of disease or mortality. Although quality of life measures were developed mainly to reflect the consequences of health problems, losses in sense of wellbeing may conceivably precede, follow, or be independent of disease. Cederblad ${ }^{13)}$ found SOC as the best correlate of health and mental well-being in a group of middle-aged subjects, considered to be at risk for psychiatric disturbances, who were drawn from a longitudinal study in Sweden. Other reports also focused mainly on the modifying effect of SOC to the quality of life in specific diseases ${ }^{14}$. In this study we tried to observe the movement of well-being in apparently normal working people and the contribution of job demand and control, as psychological work stress markers, and sense of coherence (SOC), as a construct that measures outlook on life against stressful conditions, to this movement by evaluating indicators of health related quality of life in a period of one year.

\section{Methods}

This study is in collaboration with the Whitehall II study ${ }^{15)}$ which was set up to investigate the degree and cause of the social gradient in morbidity and mortality in a cohort of civil servants in London.

In this 1-year follow-up study we evaluated 2100 civil servants working in departments related to the municipality of T city in Toyama prefecture, Japan, in the springs of 2001 and 2002. From the original population 1682 (80.9\%) subjects participated in the first phase of the study. In the second phase, questionnaire was sent to all 2100 subjects from whom $1718(81.8 \%)$ responded. In the second phase $5 \%$ of the original population in 2001 retired and $2.5 \%$ were new employees recruited in 2002. Finally data for 1392 (66.3\%) subjects who had complete information for the first and second phases were analyzed.

We divided the civil servants into four groups based on the classification system used in the national census ${ }^{16)}: 1$ ) Administrative, 2) Professional, 3) Clerical and 4) Protective, Transportation and Telecommunication service workers who we put into the Office Support category. We also stratified the age of the participants into four groups: 29 or younger, 30 39, 40 49 and 50 years or older.

\section{Questionnaire}

QOL: The Japanese version of WHOQOL-BREF (WHO/
QOL-26 ${ }^{17)}$ ) was used for this study. The WHO/QOL-26 contains a total of 26 questions which consist of the following domains: 1) Physical Health (7 questions), 2) Psychological (6 questions), 3) Social Relationships (3 questions), and 4) Environment (8 questions). The four domain scores denote an individual's perception of the quality of life in each particular domain. Domain scores are scaled in a positive direction, i.e. higher scores denote a higher quality of life. The raw score of items within each domain is used to calculate the domain score. The domain score is then converted to a transformed score (range of score: 4-20). The method for converting raw scores to transformed scores is given elsewhere ${ }^{17)}$, where more than two items were missing from the domain, the domain score was not calculated (with the exception of the Social Relationships domain).

SOC: We used the Japanese version of SOC- $13^{18)}$ for our survey. The items were rated on a seven-point likert scale in which higher values indicate a stronger SOC. The scale consists of three dimensions: comprehensibility, manageability and meaningfulness, which are equally weighted and together make an overall score.

Psychological work characteristics: The questionnaire used in the Whiltehall II study ${ }^{2)}$ to report the work environment characteristics (based on Karasek's job strain model) was adopted for this study to assess job strain ${ }^{19}$. Face and content validity plus internal consistency-reliability (results) was satisfactory for the scale, which had already been used in other fields in Japan and also in other countries. We used job demand and control as continuous variables by rating on a four-point likert scale in which higher values indicate higher control and demand at workplace.

Negative affectivity is the disposition to respond negatively to questionnaires and may overestimate or underestimate correlations between self reported work characteristics and self reported health and disease ${ }^{20,21)}$. Negative affectivity was measured with the negative affect subscale of the affect balance scale.

The scales of psychological work characteristics, SOC13 and negative affectivity were measured in the first phase and WHO/QOL-26 was measured both in the first and second phases of the study.

\section{Statistical analysis}

To detect the differences in the mean values of WHO/ QOL-26 components' scores between the first and second phase we performed paired t-test after stratifying for the age and gender of the participants. We also used multiple linear regression analysis with the WHO/QOL-26 scores in the second phase as dependent variable and the first phase 
Table 1. Paired t-test-Mean \pm SD for domains of WHO/QOL-26 in first and second phases, stratified for age and sex of the subjects

\begin{tabular}{|c|c|c|c|c|c|c|c|}
\hline \multirow[t]{2}{*}{ Age } & \multirow[t]{2}{*}{$\mathrm{N}(\%)$} & \multicolumn{2}{|c|}{ Physical Health } & \multicolumn{4}{|c|}{ Psychological } \\
\hline & & $1 \mathrm{st}$ & 2 nd & $\mathrm{P}$ & $1 \mathrm{st}$ & 2 nd & $\mathrm{P}$ \\
\hline \multicolumn{8}{|l|}{ Male } \\
\hline$<29$ & $37(4.7 \%)$ & $13.6 \pm 3.66$ & $12.9 \pm 2.19$ & 0.25 & $12.0 \pm 2.65$ & $12.2 \pm 2.30$ & 0.55 \\
\hline $30-39$ & $51 \quad(6.5 \%)$ & $12.9 \pm 3.02$ & $12.8 \pm 2.27$ & 0.76 & $12.2 \pm 2.37$ & $12.1 \pm 2.19$ & 0.6 \\
\hline $40-49$ & $352(45.1 \%)$ & $13.6 \pm 3.26$ & $12.6 \pm 2.19$ & 0.001 & $11.7 \pm 2.15$ & $11.6 \pm 2.21$ & 0.37 \\
\hline$>50$ & $340(43.6 \%)$ & $14.1 \pm 3.25$ & $13.1 \pm 2.08$ & 0.001 & $12.2 \pm 2.01$ & $12.3 \pm 2.15$ & 0.54 \\
\hline \multicolumn{8}{|l|}{ Female } \\
\hline$<29$ & $66(10.8 \%)$ & $13.6 \pm 3.32$ & $12.6 \pm 1.85$ & 0.02 & $11.7 \pm 2.06$ & $11.9 \pm 2.34$ & 0.39 \\
\hline $30-39$ & $27(4.4 \%)$ & $12.3 \pm 3.94$ & $12.1 \pm 2.14$ & 0.78 & $11.3 \pm 2.40$ & $11.6 \pm 2.86$ & 0.46 \\
\hline $40-49$ & $288(47.0 \%)$ & $12.5 \pm 3.48$ & $11.4 \pm 2.01$ & 0.001 & $11.3 \pm 2.08$ & $11.2 \pm 2.03$ & 0.56 \\
\hline$>50$ & $231(37.7 \%)$ & $12.5 \pm 2.84$ & $11.9 \pm 2.25$ & 0.001 & $11.5 \pm 2.21$ & $11.5 \pm 2.23$ & 0.95 \\
\hline \multirow[t]{2}{*}{ Age } & \multirow[t]{2}{*}{$\mathrm{N}(\%)$} & \multicolumn{2}{|c|}{ Social Relationship } & \multicolumn{4}{|c|}{ Environment } \\
\hline & & $1 \mathrm{st}$ & 2 nd & $\mathrm{P}$ & $1 \mathrm{st}$ & 2 nd & $\mathrm{P}$ \\
\hline \multicolumn{8}{|l|}{ Male } \\
\hline$<29$ & $37(4.7 \%)$ & $12.6 \pm 2.15$ & $13.0 \pm 2.92$ & 0.27 & $12.2 \pm 1.96$ & $12.9 \pm 2.09$ & 0.02 \\
\hline $30-39$ & $51 \quad(6.5 \%)$ & $12.3 \pm 2.14$ & $11.8 \pm 2.06$ & 0.13 & $11.7 \pm 1.99$ & $12.0 \pm 1.77$ & 0.82 \\
\hline $40-49$ & $352(45.1 \%)$ & $11.9 \pm 2.23$ & $11.9 \pm 2.16$ & 0.80 & $11.7 \pm 1.99$ & $11.7 \pm 1.97$ & 0.92 \\
\hline$>50$ & $340(43.6 \%)$ & $12.3 \pm 1.97$ & $12.2 \pm 2.19$ & 0.44 & $12.1 \pm 1.93$ & $12.1 \pm 2.06$ & 0.63 \\
\hline \multicolumn{8}{|l|}{ Female } \\
\hline$<29$ & $66(10.8 \%)$ & $13.4 \pm 2.16$ & $12.9 \pm 2.03$ & 0.02 & $12.2 \pm 1.88$ & $12.3 \pm 1.73$ & 0.73 \\
\hline $30-39$ & $27 \quad(4.4 \%)$ & $11.9 \pm 2.22$ & $12.5 \pm 2.33$ & 0.15 & $11.3 \pm 2.01$ & $11.9 \pm 2.02$ & 0.03 \\
\hline $40-49$ & $288(47.0 \%)$ & $12.6 \pm 1.96$ & $12.5 \pm 1.96$ & 0.42 & $11.6 \pm 1.84$ & $11.6 \pm 1.73$ & 0.94 \\
\hline$>50$ & $231(37.7 \%)$ & $12.8 \pm 2.04$ & $12.5 \pm 2.04$ & 0.06 & $11.6 \pm 1.95$ & $11.7 \pm 1.95$ & 0.41 \\
\hline
\end{tabular}

scores plus age, sex, employment category, SOC, job control, job demand and negative affectivity as predictor variables to evaluate the importance of each variable on the second phase WHO/QOL-26 components' scores. In all models the $\mathrm{F}$ value for the test of overall goodness of fit was over 40 which was associated with $\mathrm{p}<0.001$. In addition, a qualitative approach to the models showed that the distribution of the residuals were normal and the plots of the residuals versus each independent variable were uniformly distributed in a symmetric band centered on a residual value of zero. As a quantitative measure we performed Cook's distance statistic ${ }^{22)}$ and we found no potential outlier, which reiterated the validity of assumptions in the regression models. All reported significance levels are $\mathrm{P}<0.05$ (two-tailed test). The data were analyzed with Dr.SPSS (version 8.0.1J).

\section{Results}

Cronbach's alpha for job control and demand were 0.77 and 0.68, respectively. Cronbach's alpha for the SOC was 0.83 and for the domains of WHO/QOL-26 in the first and second phases were 0.75 and 0.75 for Physical Health, 0.76 and 0.75 for Psychological, 0.61 and 0.62 for Social Relationship, 0.76 and 0.77 for Environment.

Mean scores for domains of WHO/QOL-26 in the first and second phases of the study have been presented in Table 1. Over 40 years of age both men and women showed significantly lower scores for Physical Health domain in the second phase. Psychological scores did not change significantly among the age groups in both sexes.

Table 2 shows the results of multiple linear regression analysis with second phase WHO/QOL-26 domain scores as dependent variable. Age was negatively associated to all domains of WHO/QOL-26, while women were more likely to have lower scores in second phase for Physical Health and Psychological domains than men. Apart from first phase WHO/QOL-26 scores, which were strongly related to the domain scores one year later, SOC was also associated with the second phase scores in all domains (standardized 
Table 2. Linear regression analysis-Associations between follow-up domains of WHO/QOL-26 (outcome measure) and predictor variables at baseline

\begin{tabular}{|c|c|c|c|c|c|c|c|c|}
\hline \multirow[t]{2}{*}{ First phase } & \multicolumn{2}{|c|}{ Physical Health } & \multicolumn{2}{|c|}{ Psychological } & \multicolumn{2}{|c|}{$\begin{array}{c}\text { Social } \\
\text { Relationship }\end{array}$} & \multicolumn{2}{|c|}{ Environment } \\
\hline & $\beta^{*}$ & $\mathrm{P}$ & $\beta$ & $\mathrm{P}$ & $\beta$ & $\mathrm{P}$ & $\beta$ & $\mathrm{P}$ \\
\hline WHO/QOL-26 & 0.26 & $<0.001$ & 0.53 & $<0.001$ & 0.46 & $<0.001$ & 0.56 & $<0.001$ \\
\hline $\operatorname{Sex}^{\dagger}$ & -0.19 & $<0.001$ & -0.06 & $<0.05$ & 0.04 & 0.14 & -0.04 & 0.12 \\
\hline Age & -0.09 & $<0.001$ & -0.06 & $<0.05$ & -0.06 & $<0.05$ & -0.08 & $<0.01$ \\
\hline Employment category & -0.07 & $<0.01$ & -0.04 & 0.07 & -0.03 & 0.18 & -0.07 & $<0.01$ \\
\hline SOC & 0.21 & $<0.01$ & 0.12 & $<0.001$ & 0.13 & $<0.001$ & 0.07 & $<0.05$ \\
\hline Job control & 0.17 & $<0.01$ & 0.12 & $<0.05$ & 0.12 & $<0.01$ & 0.05 & 0.28 \\
\hline Job demand & -0.21 & $<0.001$ & -0.10 & 0.08 & 0.09 & 0.12 & -0.03 & 0.63 \\
\hline Control $\times$ demand & -0.12 & 0.12 & -0.11 & 0.07 & 0.11 & $<0.05$ & -0.04 & 0.57 \\
\hline Negative affectivity & -0.06 & $<0.05$ & -0.03 & 0.19 & -0.01 & 0.66 & -0.05 & 0.08 \\
\hline $\mathrm{R}^{2}$ & \multicolumn{2}{|c|}{$28 \%$} & \multicolumn{2}{|c|}{$41 \%$} & \multicolumn{2}{|c|}{$33 \%$} & \multicolumn{2}{|c|}{$41 \%$} \\
\hline
\end{tabular}

$* \beta$ indicates standardized $\beta$ coefficient. ${ }^{`}$ Dummy variable (male $=0$, female $\left.=1\right)$.

$\beta$ coefficients of $0.21, \mathrm{P}<0.01 ; 0.12, \mathrm{P}<0.001 ; 0.13, \mathrm{P}<0.001$ and 0.07, $\mathrm{P}<0.05$ for Physical Health, Psychological, Social Relationship and Environment, respectively). Meanwhile, job control was positively (standardized $\beta$ coefficient of 0.10 , $\mathrm{P}<0.001$ ) and job demand negatively (standardized $\beta$ coefficient of $-0.11, \mathrm{P}<0.001)$ related to Physical Health domain. In addition job control was positively related to the second phase scores of Psychological and Social Relationship domains with standardized $\beta$ coefficients of 0.07 and $0.12(\mathrm{P}<0.05)$, respectively. The control, demand interaction was not related to WHO/QOL-26 domains except for Social Relationship. Overall the linear regression models accounted for $28 \%, 41 \%, 33 \%$ and $41 \%$ of the variance in Physical Health, Psychological, Social Relationship and Environment domains, respectively. Without entering the first phase scores, the models accounted for $22 \%, 23 \%, 18 \%$ and $18 \%$ of the variance in the WHO/QOL-26 domains (order as above).

\section{Discussion}

In this report we have shown that psychosocial characteristics could be assumed as predictable measures for self-perceived quality of life in a short follow-up period of one year. This was remarkably illustrated for SOC, while job control and demand were also related (the former positively and the latter negatively) to the Physical Health domain of WHO/QOL-26. There was also a relatively small overall mean decline in Physical Health scores over 40 years of age both in men and women.

In comparison with other health indicators such as daily activities and behavior ${ }^{23}$, , perceived health measures ${ }^{24)}$, and disability/functional measures ${ }^{25}$ which are beginning to provide a measure of the impact of disease, WHO/QOL rather assesses the quality of life per se which has its own value in health measurement.

Antonovsky's SOC ${ }^{8-11)}$ ought to explain why some people manage stress and stay well, while others breakdown. Our findings suggest that SOC can predict the movement towards health in a short period of 1-year follow-up. It indicates that those subjects who see their life as having some purpose and believe that their life tasks are worthy investments, in terms of energy and commitment as well as seeing themselves as having the personal resources to cope with the difficulties and demands that they may encounter, have better quality of life for all the domains of WHO/QOL-26.

People also may react differently to a given work environment, some perceiving high levels of stress, whereas others do not, so that some people may develop health problems more readily than others. This is illustrated by the job strain components, where job demand was negatively associated with the Physical Health of the subjects one year from the first survey, while job control was positively associated. Since the level of job demand can hardly be manipulated at workplaces, increasing the latitude of control may have an improving effect on Physical health, Psychological and Social Relationship domains of subjective quality of life. This may be achieved by adopting measures for work characteristics in order to give more decision authority to civil servants after considering its feasibility for each organization.

Interaction term of job demand and control was only turned 
significant in predicting Social Relationship domain. Since the association between job control and Social Relationship was stronger than that of interaction, it may suggest that workers with higher job control and demand seek better social relationship probably to contrast with higher work pressure, but it was just the case for those with higher control in their job.

There were not any significant changes in Psychological domain between first and second phase of the study among age groups in men and women. A large cross sectional study in Britain has suggested that mental health remains stable across middle age and if anything is better for the 55-64 year olds ${ }^{26)}$. Meanwhile, Martikainen ${ }^{27)}$ reported from the Whitehall II study that adjustment for job decision latitude accounted for a large part of the differences in positive change of mental functioning and to a lesser extent physical functioning in a three year follow-up study. In this regard our findings were consistent with the Whitehall II results by observing that job control was associated with Physical Health, Psychological and Social Relationship domains despite a short follow-up period of one year.

The physiological and clinical significance of this shortterm decline in self-reported measures of Physical Health is not clear, but one possibility is that it reflects early stages of more serious morbidity.

The limitations of our study mainly go back to the selfreported nature of the scales. Information bias is a potential source of bias in self-reported studies. However, a fairly large study population and also entering the measure of negative affectivity into the models along with other variables could minimize the effect of information bias on the results. Since we lost almost $34 \%$ of the original population in the second phase of the study we cannot rule out follow up bias. However, $20 \%$ of the subjects did not participate in the first phase while $2.5 \%$ of the entire second phase population were new employees. Therefore, we lost almost $12 \%$ of the participants in the follow up but there was no significant difference in the first phase WHO/QOL-26 domain scores between those who participated in both phases and those who did not participate in the second phase. Regarding multicollinearity between independent variables there were low correlations between Physical Heath, SOC, Job control and demand, while as we expected the highest correlation was found between SOC and Psychological domain ( $\mathrm{r}=0.51$, $\mathrm{P}<0.001)$. Meanwhile, there was no large variance inflation factor for each independent variable in all models. It is also worth noting that since subjective sense of well-being may be affected by other variables including diet, material problems, life events, etc. our model which focused mainly on psychosocial characteristics illustrates partly the factors contributed in change of quality of life in a period of one year.

In conclusion our findings have indicated that sense of coherence could modify the subjective feeling of well-being and there are also reasons to believe that higher decision latitude at workplace could result in better subjective Physical Health, Psychological and Social Relationship in a 1-year follow-up among our sample of Japanese civil servants.

\section{Acknowledgement}

The Authors are very grateful to the Municipality of T city in Toyama Prefecture, Japan, for their support and cooperation in this study, all participating departments and civil servants and all the study team in particular Mrs Yoriko Yoshida, Yasuko Yamazaki and Noriko Annen for data collection and clerical support.

\section{References}

1) Bosma H, Peter R, Siegert J, Marmot MG (1998) Two alternative job stress models and the risk of coronary heart disease. Am J Public Health 88, 68-74.

2) Bosma $H$, Marmot MG, Hemingway $H$, Nicholson $A$, Brunner EJ, Stansfeld S (1997) Low job control and risk of coronary heart disease in the Whitehall II (prospective cohort) study. BMJ 314, 558-65.

3) Lerner DJ, Levine S, Malspeis S, D’ Agostino RB (1994) Job strain and health-related quality of life in a national sample. Am J Public Health 84, 1580-5.

4) Marmot MG, Bosma H, Hemingway H, Brunner E, Stansfeld S (1997) Contribution of job control and other risk factors to social variations in coronary heart disease incidence. Lancet 350, 235-9.

5) North FM, Syme SL, Feeney A, Shipley M, Marmot MG (1996) Psychosocial work environment and sickness absence among British civil servants: The Whitehall II study. Am J Public Health 86, 332-40.

6) Schnall PL, Landsbergis PA, Baker D (1994) Job strain and cardiovascular disease. Annu Rev Public Health 15, 381-411.

7) Schnall PL, Schwartz JE, Lansbergis PA (1992) Relation between job strain, alcohol and ambulatory blood pressure. Hypertension 19, 488-95.

8) Antonovsky A (1979) Health, stress and coping: New perspective on mental and physical well-being. JosseyBase, San Francisco.

9) Antonovsky A (1987) Unravelling the mystery of health. 
Jossey-Bass, San Francisco.

10) Antonovsky A (1993) The structure and properties of the sense of coherence scale. Soc Sci Med 36, 725-33.

11) Antonovsky A(1996) The salutogenic model as a theory to guide health promotion. Health Promot Internation 11, 11-8.

12) Levine $\mathrm{S}$, Croog SH (1984) What constitutes quality of life? A conceptualization of the dimensions of life quality in healthy populations and patients with cardiovascular diease. In: Assessment of quality of life in clinical trials of cardiovascular therapies. eds. by Wenger NK, Mattson ME, Furberg CD, Elinson J, 4666, LeJacq Publications, New York, NY.

13) Cederblad M, Hansson K (1996) Sense of coherencea concept influencing health and quality of life in a Swedish psychiatric at risk group. Isr J Med Sci 32, 194-9.

14) Klevsgard R, Risberg BQ, Thomsen MB, Hallberg IR (2001) A 1-year follow-up quality of life study after hemodynamically successful or unsuccessful surgical revascularization of lower limb ischemia. J Vasc Surg 33, 114-22.

15) Marmot MG, Smith GD, Stansfeld S, Patel C, North F, Head J, White I, Brunner E, Feeney A (1991) Health inequalities among British civil servants: the Whitehall II study. Lancet 337, 1387-93.

16) Management and Coordination Agency (1995) the national government of Japan. The 1995 census.

17) Tazaki M, Nakane Y (1997) WHOQOL-26 information. Kk. Kaneko Shobou, Tokyo (in Japanese).

18) Yamazaki Y (1999) SOC: A new health perspective; An ability to shaping and preserving health. Quality Nursing 10, 81-9 (in Japanese).
19) Nasermoaddeli A, Sekine M, Hamanishi S, Kagamimori S (2002) Job strain and sleep quality in Japanese civil servants with special reference to sense of coherence. J Occup Health 44, 337-42.

20) Brief AP, Burke MJ, George JM, Robinson BS, Webster J (1988) Should negative affectivity remain an unmeasured variable in the study of job stress? J Appl Psychol 73, 193-8.

21) Kressin NR, Spiro A3rd, Skinner KM (2000) Negative affectivity and health-related quality of life. Med Care 38, 858-67.

22) Glantz SA, Slinker BK (1990) Primer of applied regression and analysis of variance. 136-41, Mc Grawhill, New York.

23) Bergner M, Bobbit RA, Carter WB (1981) The sickness impact profile: Development and final revision of a health status measure. Med Care 19, 787-805.

24) Hunt SM, McKenna SP, McEwan J (1989) Measuring Health Status. The Nottingham health profile. Users Mannual. Revised edition, Routledge and Kegan Paul, London.

25) Ware JE, Snow K., Kosinski M, Gandek B (1993) SF36 health survey: Manual and interpretation guide. New England Medical Center, Boston.

26) Jenkins R, Lewis G, Bebbington $P$, Brugha $T$, Farrel M, Gill B, Meltzer H (1997) The national psychiatric morbidity surveys of Great Britain- initial findings from the household survey. Psychol Med 27, 775-89.

27) Martikainen P, Stansfeld S, Hemingway H, Marmot M (1999) Determinants of socioeconomic differences in change in physical and mental functioning. Soc Sci Med 49, 499-507. 